Delft University of Technology

\title{
The Effect of Maneuver Load Alleviation Strategies on Aircraft Performance Indicators
}

Mancini, Andrea; Roelofs, Martijn; Vos, Roelof

DOI

10.2514/6.2019-3272

Publication date

2019

Document Version

Final published version

Published in

AIAA Aviation 2019 Forum

\section{Citation (APA)}

Mancini, A., Roelofs, M., \& Vos, R. (2019). The Effect of Maneuver Load Alleviation Strategies on Aircraft Performance Indicators. In AIAA Aviation 2019 Forum (pp. 1-17). [AIAA-2019-3272] (AIAA Aviation 2019 Forum). American Institute of Aeronautics and Astronautics Inc. (AIAA). https://doi.org/10.2514/6.2019-3272

\section{Important note}

To cite this publication, please use the final published version (if applicable).

Please check the document version above.

\section{Copyright}

Other than for strictly personal use, it is not permitted to download, forward or distribute the text or part of it, without the consent of the author(s) and/or copyright holder(s), unless the work is under an open content license such as Creative Commons.

\section{Takedown policy}

Please contact us and provide details if you believe this document breaches copyrights.

We will remove access to the work immediately and investigate your claim. 


\title{
The Effect of Maneuver Load Alleviation Strategies on Aircraft Performance Indicators
}

\author{
Andrea Mancini, ${ }^{*}$ Martijn Roelofs ${ }^{\dagger}$ and Roelof Vos ${ }^{\ddagger}$ \\ Delft University of Technology, Delft, Zuid-Holland, 2600AA, the Netherlands
}

\begin{abstract}
The need to reduce the pollutant impact of aircraft emission drives the research on aircraft design progress through off-design performance improvement. This report proposes to investigate the effect of maneuver load alleviation technology via wing control surfaces for this purpose. A methodology is presented to model the MLA technology in aircraft conceptual design and to evaluate its impact on both existing and clean-sheet design. In addition, the possibility to consider flexible wings when under the influence of $2.5 \mathrm{-g}$ maneuver loads is addressed, to assess the impact of aeroelasticity in on wing weight in the conceptual design phase. The aeroelastic analysis method is validated against a higher-order analysis method with excellent correlation between the results from the two methods. Subsequently, the method is applied to the redesign of medium-range, single-aisle aircraft. It is shown that applying MLA using both the flaps and the ailerons can result in a fuel burn reduction and maximum take-off mass reduction of $2.1 \%$ and $2.2 \%$, respectively.
\end{abstract}

\section{Nomenclature}

\author{
sectional area $\left(\mathrm{m}^{2}\right)$ \\ wing span $(\mathrm{m})$ \\ wing chord (m) \\ mean aerodynamic chord $(\mathrm{m})$ \\ local lift coefficient $(\sim)$ \\ lift curve slope (1/rad) \\ displacement vector $(\mathrm{m})$ \\ Young's modulus $\left(\mathrm{N} / \mathrm{m}^{2}\right)$ \\ gravitational acceleration $\left(\mathrm{m} / \mathrm{s}^{2}\right)$ \\ shear modulus $\left(\mathrm{N} / \mathrm{m}^{2}\right)$ \\ second moment of area $\left(\mathrm{m}^{4}\right)$ \\ polar moment of inertia $\left(\mathrm{m}^{4}\right)$ \\ objective function $(\mathrm{Nm})$
}

$L \quad$ element length (m)

$M \quad$ bending moment $(\mathrm{Nm})$

$\begin{array}{ll}K & \text { stiffness matrix }(\mathrm{N} / \mathrm{m}) \\ K_{g} & \text { gust alleviation factor }(\sim)\end{array}$

$l \quad$ distributed lift $(\mathrm{N} / \mathrm{m})$

$R \quad$ external forces vector $(\mathrm{N})$

$s \quad$ distributed shear force $(\mathrm{N})$

$S \quad$ wing surface area $\left(\mathrm{m}^{2}\right)$

$T$ thrust (N)

$U_{e} \quad$ equivalent gust velocity $(\mathrm{m} / \mathrm{s})$

$V \quad$ airspeed $(\mathrm{m} / \mathrm{s})$

$V_{A} \quad$ maneuver speed $(\mathrm{m} / \mathrm{s})$

$V_{D} \quad$ dive speed $(\mathrm{m} / \mathrm{s})$

$W \quad$ weight $(\mathrm{N})$

$\alpha \quad$ angle of attack (deg)

$\delta \quad$ control surface deflection angle (deg)

$\mu \quad$ mass ratio $(\sim)$

$\rho$ density $\left(\mathrm{kg} / \mathrm{m}^{3}\right)$

\section{Introduction}

Rising environmental concerns nowadays are drawing more attention to the quest towards energy-efficient aircraft. According to European aviation goals, a drastic reduction in current pollutant and noise emissions is sought before the year 2050, aiming at a $75 \%$ and $90 \%$ reduction of $\mathrm{CO}_{2}$ and $\mathrm{NO}_{\mathrm{x}}$, respectively, together with a $65 \%$ cutback in noise level [1]. Such an ambitious goal endorses deeper research towards greener aircraft, featuring a reduction in fuel burn. The 4.8\% annual growth prediction of passenger air traffic [3] also intensifies the need for more fuel-efficient aircraft. There are different measures that can be taken to reduce fuel consumption. A major one consists in the reduction of the

\footnotetext{
*MSc student, Faculty of Aerospace Engineering, Delft University of Technology, Kluyverweg 1 2629HS, Delft, The Netherlands.

${ }_{\dagger}^{\dagger} \mathrm{PhD}$ candidate, Faculty of Aerospace Engineering, Delft University of Technology, Kluyverweg 1 2629HS, Delft, The Netherlands, Member AIAA.

† Assistant Professor, Faculty of Aerospace Engineering, Delft University of Technology, Kluyverweg 1 2629HS, Delft, The Netherlands, Associate Fellow AIAA.
} 
aircraft weight. Less fuel is required to realize the same mission with the same payload if the aircraft structural weight is lower. Reduction in the aircraft weight is also proportional to lower operating costs, increasing the design appeal for the airlines.

The load alleviation concept is an elegant solution to reduce weight. Aircraft wings are structurally sized for the worst case scenario, high maneuver loads, but aerodynamically optimized for the cruise condition. The optimal aerodynamic load distribution is represented by an elliptical shape, which minimizes the induced drag [4]. However, when the same wing geometry is used to attain the higher loads required for the structural sizing, the spanwise lift distribution is not optimal: generating the majority of the lift inboard to reduce the structural stress would be more convenient. To do so, the wing shape could be modified during maneuvers to optimize the load distribution to achieve a less severe structural loading [5-7]. The wing is should then be able to change its shape accordingly to flight conditions [8] or to external loads [9], aiming at a potential weight and fuel-burn reduction [10, 11].

Wing morphing is one of the ways to achieve such a change in wing shape under high-load conditions. However, a morphing wing requires a complex design, since it is constrained by a set of conflicting requirements: the structure has to simultaneously carry loads without deformation, change its shape with low actuation loads, and be light weight at the same time. An easy solution to reshape the load distribution is by employing the wing control surfaces. These are already present on the aircraft, thus no further modification of the classical wing structure is necessary. Control surfaces to alleviate loads are currently utilized by some aircraft manufacturers [12, 13]. When camber variation is used for load alleviation, it is also important to take into account control-surface-induced aerodynamic twist, since this deformation changes the lift distribution [14].

There are multiple ways to model load alleviation (MLA): when optimizing the wing structure by keeping the wing planform constant, the control surfaces deflection angles are considered design variables, and the objective function could be the wing mass [6] or the wing root bending moment [15]. The results from Stanford [6] present a 30\% wing mass reduction. Alternatively, MLA can be modeled in wing planform design by specifying as optimization objective the drag [16]. In this case, the wing tends to a higher aspect ratio which reduces the drag. Xu et al. [17] insert MLA within aircraft design, while optimizing for the direct operating cost. The results show a wing weight reduction of $13 \%$, followed by a 5\% fuel reduction. However, when MLA is active, dynamic aspects such as flutter and gust loads start to become sizing and should be considered, reducing the obtained benefits.

It is, however, of interest to investigate the effect of MLA system in the cycled aircraft design process, in order to quantify its effects on a clean-sheet airplane design. This paper therefore proposes a methodology to evaluate the effect of load alleviation during the conceptual design phase and applies this methodology to a the design of a single-aisle, medium-range aircraft. Two cases are considered: the impact of the MLA technology on an existing (uncycled) design and the impact of MLA technology on a clean sheet (cycled) design. The presented method also includes the aeroelastic deformation resulting from control-surface deflection.

This paper is organized as follows. In Section [I] the methodology to model the maneuver-load alleviation system is presented. The validation of this method is presented in section III where the results of the method are compared to the results of a higher-order analysis method as well as to experimental data. Finally, in Section IV the method is applied to a test case, and the effects of MLA on aircraft-level figures of mertit in cycled and uncycled aircraft design are discussed. In addition, sensitivity studies are performed to see the effect of design choices on these figures of mertit.

\section{Methodology}

In order to evaluate the effect of Maneuver Load Alleviation on aircraft design, the automated aircraft design software is used. TU Delft's Aircraft Design Initiator is a preliminary aircraft design tool, which' main aim is to quickly obtain the conceptual design of transport aircraft, following some specifications given as input. The entire software is coded using object-oriented programming in Matlab [18]. In this section the methodology developed to obtain a load alleviation module within the Initiator is presented. First, a general overview of the MLA module is presented in Section III.A. In Section II.B the maneuver-load alleviation method is further detailed. In Section II.C the optional aeroelastic analysis method is presented. Moreover, Section III.D discusses the load alleviation strategy as well as the equivalent static gust load that is considered.

\section{A. Module Work Flow}

The proposed MLA analysis module refines the evaluated mass of the wing utilizing quasi-analytical methods, simulating the presence of MLA technology for the designed aircraft. It is required to know beforehand the geometry of the wing and control surfaces. Therefore, the module is added in the last part of the design workflow of the Initiator. The work 
flow of the MLA module is shown in Figure 1. Two cases can be considered here: 1. a stiff wing where the aeroelastic loop is not run and 2. a flexible wing where the aeroelastic module is run until convergence is reached. Obviously, the first case is faster, while the second case is more Representative. In case of severe load conditions, such as the $2.5 \mathrm{~g}$ pull-up maneuver case here analyzed, the structural deflections can be substantial. In fact, current Federal Aviation Regulation FAR 25.301(c) states: "If deflections under load would significantly change the distribution of external or internal loads, this redistribution must be taken into account" [25]. Is therefore interesting to investigate the effect of aeroelasticity when modeling a load alleviation technology during the early phases of aircraft design

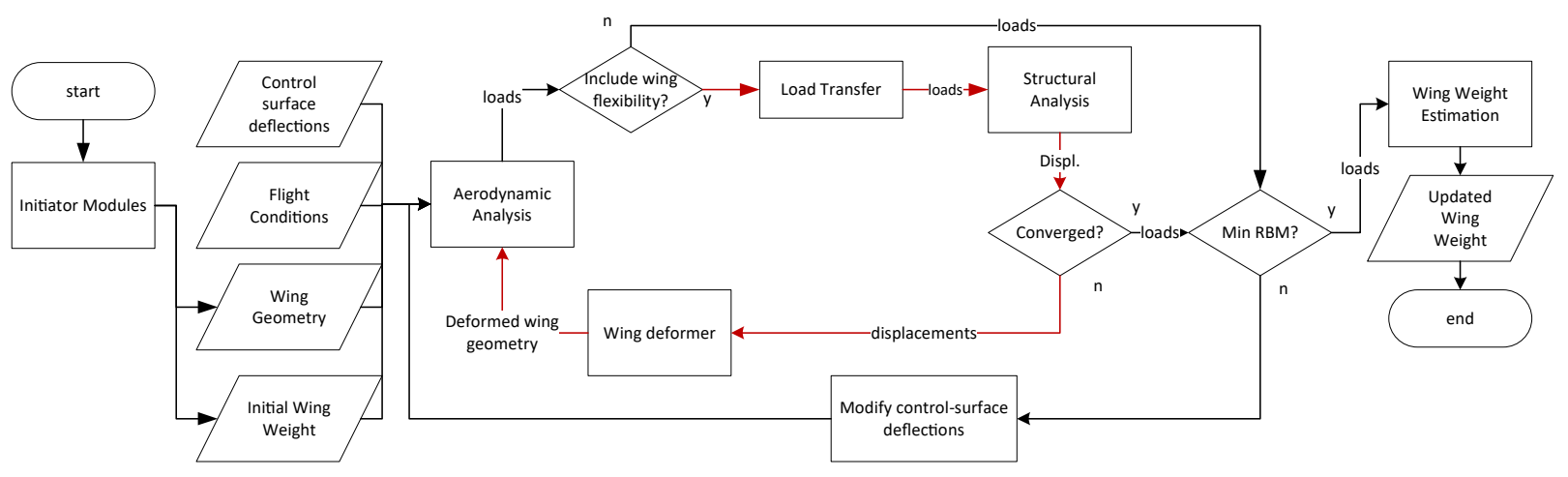

Fig. 1 MLA module workflow with with optional aeroelastic inner loop in red

As summarized in Figure 1 the tool requires as input the same flight condition and wing geometry definition needed for the aerodynamic analysis, together with extra geometrical parameters that describe the internal layout of the wing structure, such as spar location and wingbox panels thicknesses. As output, the tool provides the "corrected" aerodynamic loads due to wing flexibility. In order to evaluate the wing deflection due to the aerodynamic loads acting on it, a structural solver is required. The aeroelastic module is then completed by two additional geometrical components, which convert the aerodynamic output in the structural input, and vice versa. These two component are named Load Transfer and Deformer, and are represented together with the complete module workflow in Figure 1. Finally, when the alleviated spanwise load distribution is known, the EMWET module described in section II.B.4 is run. A new wing structure is computed, and the new wing mass is evaluated. This represent the conclusive output of the MLA module.

The system displayed in Figure 1 is usually defined as a loosely coupled aeroelastic architecture [26, 27]. The distinctive feature of such architecture is to perform the aerodynamic and structural analysis in two separate modules, which are then connected by a geometrical interface tool. Both analyses are repeated till the displacements evaluated by two consecutive iterations are converging. The wing structure and geometry are assumed to be invariable throughout the iterations. The main advantages of a loosely coupled architecture are a more straightforward approach to aeroelasticity and an increased flexibility of the tool. This model allows to use off-the-shelf, validated software tailored to solve a specific discipline, such as AVL. Moreover, it is possible to switch on or off the aeroelastic correction of the aerodynamic loads, assessing the effect of wing flexibility in load alleviation.

\section{B. Maneuver Load Alleviation Method}

The maneuver load alleviation method consists of various components that are further detailed in this section. The method works for the assumption of rigid wings as well as for flexible wings.

\section{Input to the Method}

As discussed in the previous section, the wing control surfaces are used to modify the spanwise load distribution. In the AVL environment, it is possible to define a control surface inside the geometry input file, by specifying the two limiting spanwise sections and the chordwise location of the hinge line around which the control tab rotates. Furthermore, a specific deflection angle $\delta$ can be defined, which accordingly pivots the local sectional camber line. To model the control surfaces in AVL, a new movable object class is defined in the Initiator. Each movable object is defined by an unique name, together with its spanwise and chord-wise locations. The resulting wing presents three main control 
surfaces: an inboard flap, an outboard flap and an aileron. The inboard flap spans from the wing-fuselage intersection to the kink, followed by the outboard flap. The aileron is extended from the outboard flap to the $95 \%$ of wing span.

The choice of the sizing flight condition is relevant for the final result. Sizing maneuvers are defined by the Federal Aviation Administration (FAA) and European Aviation Safety Agency (EASA) regulations, and are usually represented in a $V-n$ graph. The critical maneuver is a $2.5 \mathrm{~g}$ symmetrical pull-up at two different airspeed: the maneuver speed $V_{A}$ and the dive speed $V_{D}$.

$V_{A}$ is the equivalent speed at which the limit load is reached at the maximum design coefficient without stalling, thus at a very high angle of attack and at the slowest speed possible. Dive speed is the highest speed reachable, therefore the $2.5 \mathrm{~g}$ maneuver is executed at a lower angle of attack. In the proposed analysis, $V_{D}$ is defined as $40 \%$ higher than cruise equivalent speed. Both cases will be investigated to ensure the ability of the wing structure to resist along all the load diagram.

\section{Aerodynamic Analysis}

The aerodynamic analysis is done with the open source software AVL, which can assess the aerodynamic properties of 3D surfaces [22]. This method is widely applied in the aerospace research thanks to its fast calculation time. However it presents some limitations that must be taken into account. First of all, due to the representation of lifting surfaces with their camberline, the tool is more suited for thin surfaces at modest angle of attack. The method lacks the capacity of detecting flow separation and stall as well. Also, quasi-steady flow is assumed, which limits the usage of AVL to very low frequencies in oscillatory motions. Finally, the software uses the Prandtl-Glauert transformation to deal with flow compressibility. This correction is not reliable for high Mach numbers in the transonic regime.

From a modeling perspective, the main input parameters include the geometry definition of the lifting surfaces, as well as the flight condition. A surface is defined by its delimiting sections. A section is uniquely defined by six parameters: its leading edge coordinates $\left(X_{L E} ; Y_{L E} ; Z_{L E}\right)$, its chord, its airfoil and its local incidence angle. This last parameter can be used to define the variable wing twist along the span. The software linearly interpolates the input data to describe all the points in between two consecutive sections. More than one aerodynamic surface can be defined. In this study, apart from the wing, also the horizontal tail is included in order to study the trimmed aircraft behaviour. The wing surface is divided in a grid of a user-specified chordwise and spanwise panels, each one of them containing a vortex. Beside the number of panels, also their distribution can be specified, choosing between an equal or sinusoidal distribution. AVL's main output are the aerodynamic parameters, such as lift coefficient, induced drag coefficient and angle of attack. The lift and moment coefficient distributions along the main wing span are of primary importance for the MLA module.

\section{Wing Root Bending Moment Evaluation}

The wing root bending moment (RBM) due to the distributed aerodynamic load is the figure of merit for the load alleviation optimization routine. According to the Euler-Bernoulli beam model, the relation between bending moment $(M)$, shear force (s) and distributed load (1) is as follows [24]:

$$
\begin{gathered}
\mathrm{d} s=l \mathrm{~d} y \\
\mathrm{~d} M=s \mathrm{~d} y
\end{gathered}
$$

For a cantilever beam that represents a wing, two boundary conditions are defined at the wing tip:

$$
\begin{gathered}
s(b / 2)=0 \\
M(b / 2)=0
\end{gathered}
$$

where $b$ represents the wing span.

The distributed aerodynamic load $l$ from Equation (1) is evaluated from AVL aerodynamic outputs:

$$
l(y)=\frac{1}{2} \rho V^{2} c c_{l}
$$

where $\rho$ is the air density, $V$ is the airspeed, $c$ the local chord and $c_{l}$ the local lift coefficient. The $y$-axis has its origin at the symmetry plane letting $y$ span from 0 to $b / 2$. Equations $(1)$ and 2 are then numerically solved using the trapezoid rule. The resulting root bending moment is the moment distribution at the symmetry plane of the wing, i.e. $M(0)$. 


\section{Wing Weight Estimation}

When the MLA loop has found the minimum root-bending moment (RBM) and the final control surfaces deflections are obtained, the wing weight is estimated with the EMWET weight estimation method [19]. Its main purpose is to estimate the wing mass through a quasi-analytical approach. This method requires as input geometrical parameters of both wing and wingbox, the flight condition in terms of speed and altitude and the maximum take-off weight and the maximum zero-fuel weight. EMWET sizes the panels of the wing box based on the aerodynamic loads, which are provided by AVL. It provides as output the wing total weight, together with the thicknesses of the wingbox panels. The wing structure is designed to withstand the most critical sizing load, represented either by a $2.5 \mathrm{~g}$ pull-up maneuver or a gust. The tool is accurate [19], thanks to its analytical methods, offering at the same time a fast evaluation time

\section{Aeroelastic Analysis Method}

To evaluate the effect of wing flexibility, an inner loop in the MLA workflow can be utilized that computes the wing deformation under loading. The intricates of the underlying models are discussed in this section.

\section{Load Transfer}

The load transfer module couples the aerodynamic loads framework to the structural one. First, the beam nodes are projected on the aerodynamic mesh, which is located at the $25 \%$ of the wing chord, where the aerodynamic results are interpolated. The loads are then rotated from the aerodynamic to the general frame of reference, and transported to the beam. The resulting structural loads are composed by the aerodynamic loads, the transport moments due to the different position of the aerodynamic and structural grid, and the aerodynamic moments. In addition, the inertia loads of the wingbox and fuel mass are also evaluated. The fuel is assumed to be distributed in the fuel tank proportionally to the section volumes. Finally, the loads and moments are converted from the general frame of reference to the beam frame of reference, which is represented in Figure 2, to be used in the resolution of Equation 6) (see Sec II.C.2.

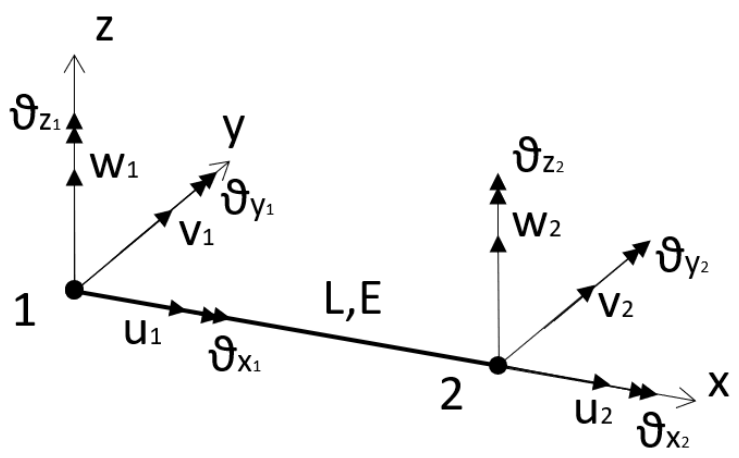

Fig. 2 3D beam element frame of reference

\section{Structural Model}

In order to capture the aeroelastic effect a structural tool is needed. For what regards an aircraft wing, the most important deformations are bending and torsion. In this study, the wingbox is represented as a finite element model based on the Euler-Bernoulli beam [28]. The wing structure is thus condensed in a mono-dimensional beam, which is subdivided in $n$ elements, all connected by $n+1$ nodes. Each element is assumed to behave linearly, which is acceptable in case of small deformations. Also, the loads considered are assumed to be static. The objective is to solve the equilibrium equation between the internal and external forces:

$$
[K]\{D\}=\{R\}
$$

where $K$ represents the structure stiffness matrix, $D$ is the displacement vector and $R$ is the vector of the external forces. To calculate the structure stiffness matrix $K$, all the matrices describing the stiffness of a single element $K_{e}$ are evaluated. Next, the distinct elements are connected, and the assembly of the element matrices provides the structural matrix $K$. Subsequently, the external loads are defined, together with the boundary conditions which describe the structure support 
condition. The external forces are the known aerodynamic and inertia loads. The linear equation system is then solved, to obtain the desired deformations.

3D Euler Beam Element In the structural model, each beam element is encompassed by two nodes at its extremities, which have 6 degrees of freedom, defined in Table 1. Figure 2 shows these degree of freedom, together with the beam local frame of reference. The structural properties of a beam element are evaluated at its center point. Since the structure is modeled as a Euler-Bernoulli beam, the beam sections are assumed to remain perpendicular to the beam axis, and to ignore the transverse shear deformation. The beam element stiffness matrix $K_{e}$ is a $12 \times 12$ symmetric matrix, where the first 6 columns are related to node 1, and the last 6 columns to the degree of freedom of node 2. It is constructed column by column, activating 1 degree of freedom at a time, subjected to an unitary displacement. The 3D beam element stiffness matrix according to Euler-Bernoulli theory is as follows:

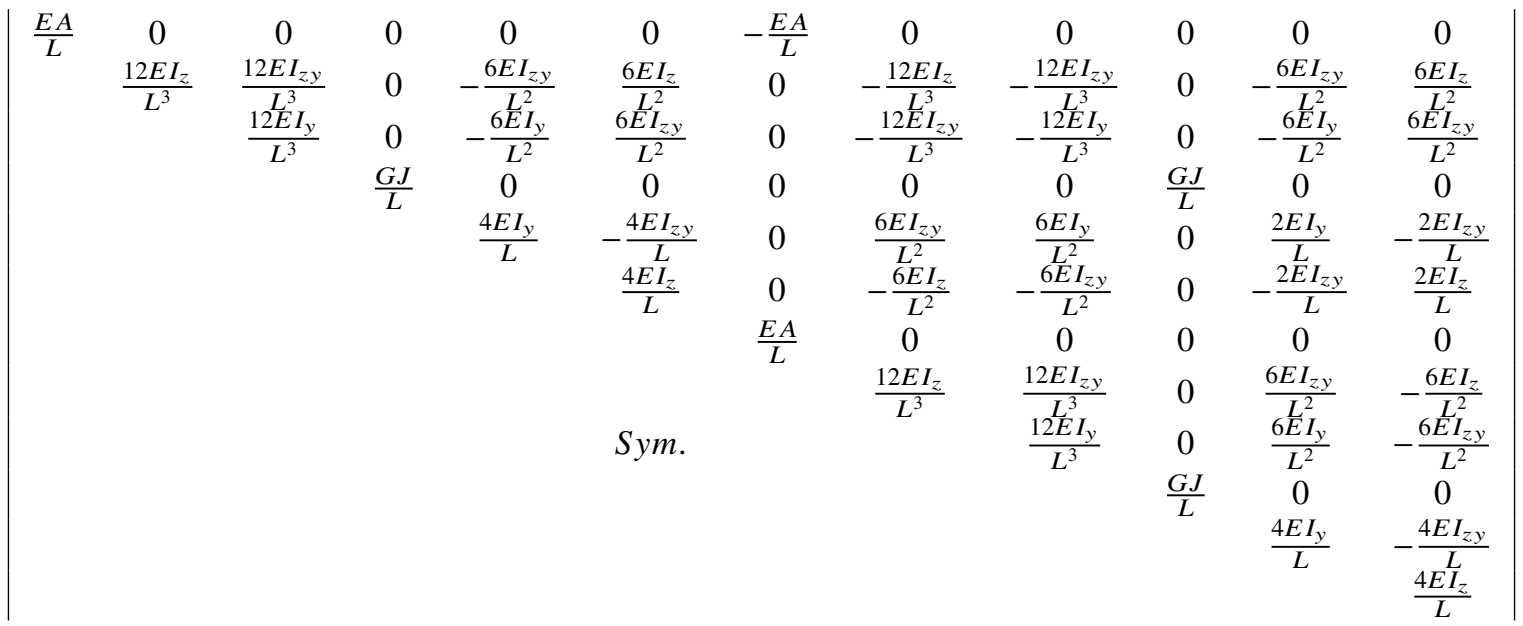

Table $13 D$ beam nodal degrees of freedom

\begin{tabular}{ccc}
\hline$u$ & $v$ & $w$ \\
axial displacement & lateral displacement in $\mathrm{y}$ & lateral displacement in $\mathrm{z}$ \\
$\theta_{x}$ & $\theta_{y}$ & $\theta_{z}$ \\
twist around the $\mathrm{x}$ axis & wing bending & lateral deflection in the $x y$ plane \\
\hline
\end{tabular}

After the element matrices are known, they are assembled to obtain the entire structure matrix $K$. In fact, each intermediate node is shared between two adjacent elements. Therefore, the displacement of a $i-t h$ node along the beam are influenced by the structural properties of both the elements it belongs to. The resulting $K$ matrix is then a symmetrical $N x N$ matrix, where $N$ is the number of beam nodes. The boundary conditions are subsequently defined. They indicate that the wing is clamped at its root. Therefore, the first beam node, which represent the wing root, is forced to have 0 deflection, which is expressed by the trivial equation $\{D\}_{1}=0$. Figure 3 shows the resulting wingbox model as a $n$ beam elements.

Element Stiffness Matrix The element stiffness matrix is defined by the cross-sectional properties of the beam. The material properties composing the wing structure are known a priori, such as its Young's modulus $E$ and its shear modulus $G$. The remaining sectional properties that must be evaluated are the second moment of area $I$ around both y and $\mathrm{z}$ axis, the product of inertia $I_{y z}$, the polar moment of inertia $J$ and the sectional area $A$, together with the element length $L$, and are defined as:

$$
A=\int_{A} \mathrm{~d} A ; \quad I_{y}=\int_{A} z^{2} \mathrm{~d} A ; \quad I_{z}=\int_{A} y^{2} \mathrm{~d} A ; \quad I_{y z}=\int_{A} y z \mathrm{~d} A ; \quad J=I_{y}+I_{z}
$$




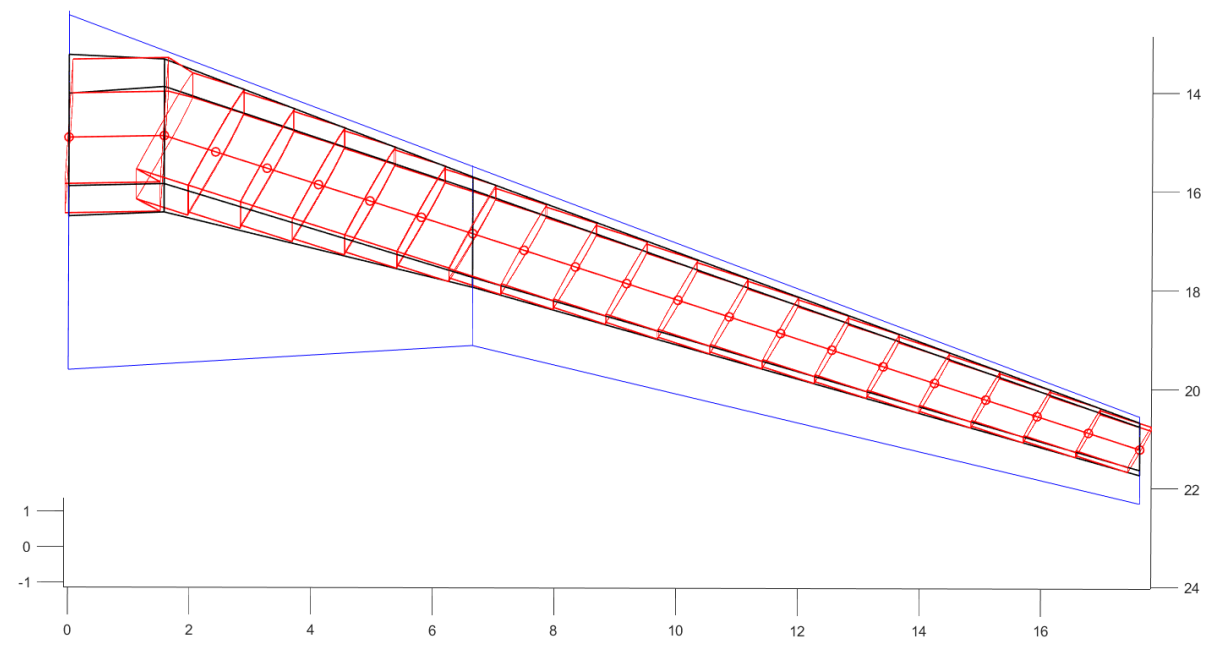

Fig. 3 Finite element representation of wingbox

The wingbox section is delimited by the two vertical spars and the upper and lower wing surface between them, where each panel has its own thickness. Since the $(y, z)$ coordinates of these panels are known, with the origin of the system located at the beam node, the properties described in Equation 7 can be numerically evaluated.

\section{Wing Deformation Method}

Once the beam deformations are evaluate, it is necessary to convert this result in an input for the aerodynamic solver. The tool in charge of this task is the deformer, which main objective is to couple the structural framework to the aerodynamic one. It receives as input the beam deformations evaluated by the structural module, it then assesses the geometry of the deformed wing and it finally codes it in an input file readable by the aerodynamic solver AVL.

The main complication is given by the difference between the structural and aerodynamic meshes. The structural mesh is represented by the beam nodes, while as presented in section II.B.2 the aerodynamic grid is defined by the section's leading edge positions and by their local twist. Therefore, it is necessary to evaluate the position of leading and trailing edge point at each section of the aerodynamic grid to fully describe the deformed wing as AVL input.

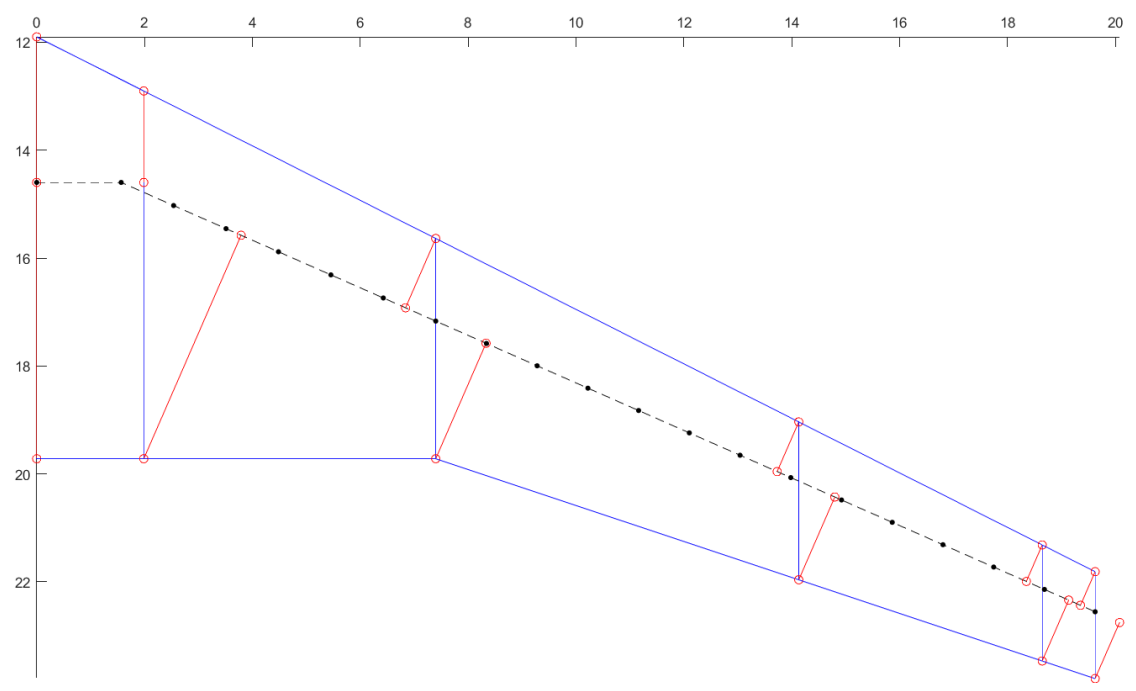

Fig. 4 Orthogonal projection of aerodynamic grid points on the beam

Figure 4 shows this process. The black dashed line represents the structural beam, while the blue contour indicates the aerodynamic grid. The red lines represent the rotation arms, connecting each aerodynamic grid point to its orthogonal 
projection on the beam. The position $r_{i}^{a}$ of a $i-t h$ point on the deformed wing is given by:

$$
\left\{r_{i}^{a}\right\}=\left\{r_{i}^{0}\right\}+\left\{\delta_{i}\right\}+\left(\left[R\left(\left\{\theta_{i}\right\}\right)\right]-\left[I_{3}\right]\right)\left\{d_{i}\right\}
$$

where $\left\{r_{i}^{0}\right\}$ is the original position of the same point, $\left\{\delta_{i}\right\}$ is the vector containing the deformations $u, v$ and $w,[R]$ is the Rodrigues matrix due to the $\left\{\theta_{i}\right\}$ deformations, $\left[I_{3}\right]$ is the unitary $3 \times 3$ matrix, and $\left\{d_{i}\right\}$ is the rotation arm. The rotation arm is the vector connecting the $i-t h$ node on the aerodynamic grid to its orthogonal projection on the closest beam element, as presented in Figure 4 The deformations $\left\{\delta_{i}\right\}$ and $\left\{\theta_{i}\right\}$ connected to each aerodynamic grid nodes are evaluated at the node's orthogonal projection, linearly interpolating between the beam nodes, where the results are known.

\section{Load Cases}

\section{Maneuver Load Alleviation Strategies}

The main objective of a maneuver load alleviation technology is to reshape the load distribution on an aircraft wing, while keeping the total amount of lift constant. If the lift is generated mostly inboard, while the load on the wing outboard part is reduced, then the moment at the wing root is lower. This allows for a lighter wingbox structure. In order to reshape the spanwise load distribution, the wing has to alter its shape by deflecting its control surfaces: small tabs, usually at the trailing edge of the lifting surface, able to rotate around a hinge. The load alleviation effect is thus characterized by a specific combination of control surfaces deflection angle $\delta$ which provides the minimum Root Bending Moment (RBM). Thus, the load alleviation routine is given by an optimization process: specifically Matlab's fmincon. The control surfaces deflection is bounded by a maximum value in both negative and positive sense, to avoid flow separation and stall to occur at the wing section. The optimization procedure can be summarized as:

minimize $J_{o}=\operatorname{RBM}(x)$ w.r.t. $x=\delta$

s.t. $l b \leq x \leq u b$

The lower and upper boundaries for the control surface deflection are important parameters, needed to prevent flow separation due to excessive deflection. For the current MLA model, the limit is established at $\pm 6^{\circ}$, consistently with other models and practical considerations [13, 17, 20, 21]. For the aerodynamic load evaluation, the trimmed aircraft case is considered: both wing and horizontal tail plane are modeled to perform the sizing pull-up maneuver, to take into account the overall aircraft angle of attack.

\section{Static Equivalent Gust Load}

Next to the maneuver loads, in FAR part 25 also the criteria to certify the aircraft against gust loads are specified. A gust load is a load condition arising when flying in turbulent air, represented by a vertical speed component, perpendicular to the flight path, which results in a sudden increase of angle of attack $\Delta \alpha$, leading to a variation in wing lift. Gust loads can become the sizing load case when MLA is active, since maneuver loads become less critical for the wing structure. To evaluate gust loads when sizing the wing structure with MLA is therefore important, to limit excessively positive results deriving from the load alleviation.

However, a gust load is a typical dynamic phenomenon, which is outside the scope of the proposed static model. A possible way to overcome this obstacle is represented by the static equivalent gust load [29, 30]. where the resulting equivalent static load factor due to a gust encounter can be derived as:

$$
n=1+\frac{K_{g} \frac{1}{2} \rho V U_{e} C_{L_{\alpha}}}{W / S}
$$

where $U_{e}$ is the equivalent vertical gust speed and $K_{g}$ is the gust alleviation factor, which is used to account for factors such as the gust gradient and aircraft response. For subsonic aircraft, it is defined as:

$$
K_{g}=\frac{0.88 \mu}{5.3+\mu}
$$

where $\mu$ is the mass ratio, equal to:

$$
\mu=\frac{2 W / S}{\rho \bar{c} C_{L_{\alpha}} g}
$$


Table 2 Validation results

\begin{tabular}{ccccccc}
\hline & $u$ & $v$ & $w$ & $\theta_{x}$ & $\theta_{y}$ & $\theta_{z}$ \\
\hline Proteus results & -0.09 & -0.39 & 4.13 & 0.31 & -0.12 & -0.01 \\
Initiator results & -0.28 & -0.39 & 4.44 & 0.35 & -0.14 & 0.01 \\
Percentage difference & $215 \%$ & $-0.2 \%$ & $7 \%$ & $11 \%$ & $26 \%$ & $-251 \%$ \\
\hline
\end{tabular}

where $\bar{c}$ is the wing mean aerodynamic chord and $g$ is the gravitational acceleration.

The equivalent gust velocity $U_{e}$ required in Equation (9), is defined by the FAR 25 regulations in section 25.341(a). Equation (9) allows to have a static equivalent gust load factor, which can be used to make sure that the wing structure would resist not only to the alleviated maneuver load, but also to a gust load. It is, however, only a first estimation, which can be improved with a proper dynamic analysis of the wing behaviour when a gust is encountered.

\section{Validation}

In this section, the model proposed in Section $\Pi$ is validated. Since the aerodynamic discipline of the aeroelastic module uses a well known and validated software program, the validation in this section is only focused on the second main discipline, i.e. the structural analysis.

\section{A. Validation with Proteus}

The TU Delft in-house aeroelastic software Proteus is used to validate the structural model. Proteus, firstly developed by Werter and De Breuker [31], is a tool for wingbox design by means of aeroelastic tailoring. The wingbox is modeled as a one-dimensional beam, which' cross sectional properties are evaluated as a Timoshenko thin-walled beam. The Timoshenko beam is considered as a higher-order analysis method compared to the Euler-Bernoulli beam assumed in this study, since it also takes into account the transverse shear deformations, which is ignored by the Euler-Bernoulli beam. The chosen test case is a representative single-aisle aircraft. Its wing and wingbox are modeled in Proteus and in the Initiator and subsequently compared. It is important to have the same starting point to properly verify the results. Both models have the front and rear spar respectively at $10 \%$ and $65 \%$ of the wing chord, with the most inboard position perpendicular to the aircraft symmetry plane, representing the wing-fuselage intersection. Moreover, both wingboxes are modeled with 20 beam elements.

The stiffness matrix $[K]$ is evaluated by both the tools, and the structural Equation $[6$ is solved for the same distributed aerodynamic loads. The resulting deformations are then compared. Table 2 shows the percentage difference of the deformations evaluated at the last node, i.e. at the wing tip. It can be observed that four out of six degrees of freedom are predicted well, while the other two are off. Out of the good predictions, $v$ is correct, while the vertical displacement $w$ and the wing twist $\theta_{x}$ are accurate. These last two parameters are the most important ones for the structural evaluation, since they are the ones with the highest influence on the aerodynamic module results. Figure 5 displays the comparison of $w$ and $\theta_{x}$ evaluation by Proteus and the Initiator along the entire wing semispan. The reason for the discrepancies in the other degrees of freedom can be found in the Timoshenko model, which can connect deformations to transverse loads. These associations are neglected in the Euler-Bernoulli beam stiffness matrix.

\section{B. Validation Against Experimental Data}

A second validation is executed against experimental data, since measurements of a twin-aisle wing in both jig- and $1 \mathrm{~g}$ shape are available. The wing belongs to the XRF-1, a 350-passenger aircraft with a range of $8000 \mathrm{nmi}$. First, the wing is modeled in the Initiator to be as close as possible to the available jig-shape. Secondly, the aeroelastic module is run for a 1-g maneuver, with all the control surfaces undeflected. Finally, the results are plotted and validated against the experimental data. Figure 6 shows the comparison between the wing leading edge position of the experimental data in black and of the evaluated model in red. The dashed lines represent the jig-shape, while the solid lines describe the 1 -g deflected shape. As one can observe, the model captures quite well the vertical displacement of the wing. The percentage difference of the vertical position of the wing tip is $4.6 \%$, which is deemed acceptable for the conceptual design phase. 


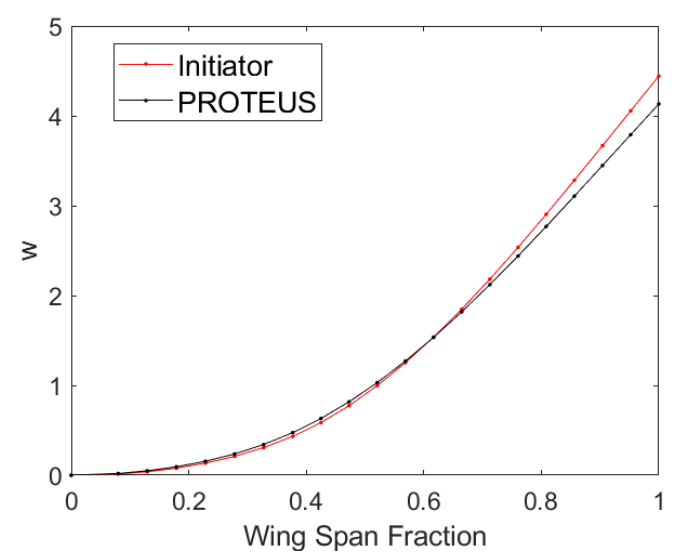

(a)

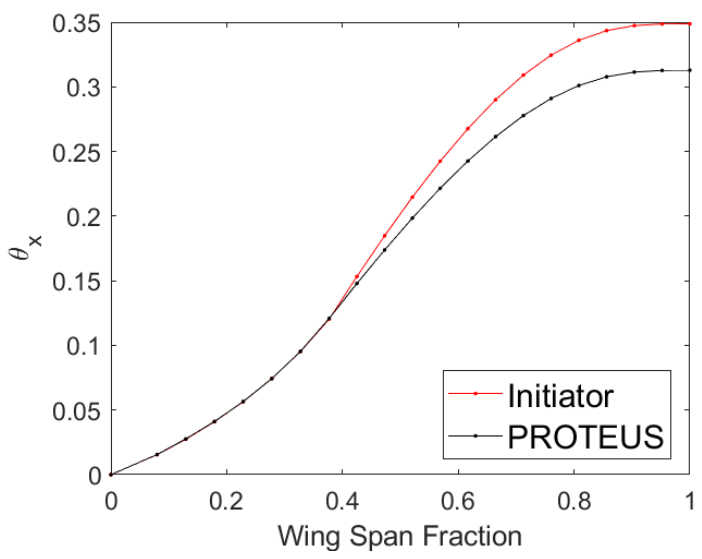

(b)

Fig. $5 \quad$ Validation of $w$ and $\theta_{x}$ predictions

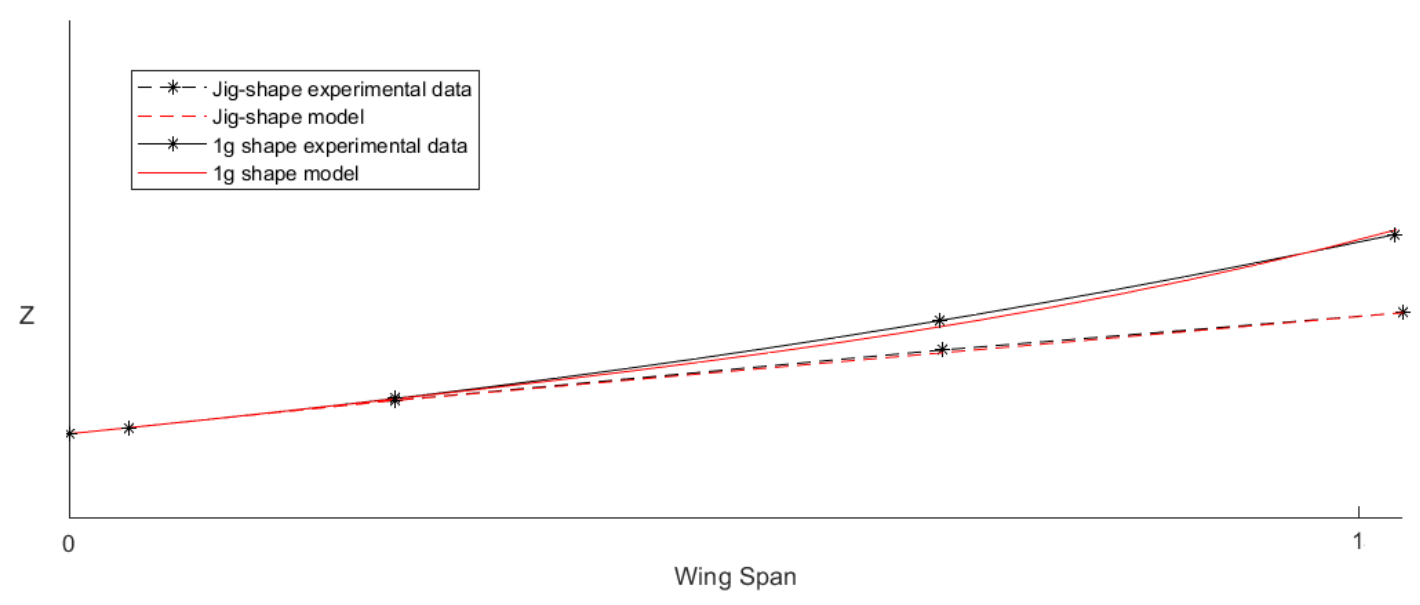

Fig. 6 Wing deflection validation against experimental data

\section{Results}

This section presents the results obtained by applying the MLA technology to the design of a single-aisle aircraft, within the Initiator framework. Firstly, the effect of the maneuver load alleviation technology is evaluated in one-cycle design loop, to focus on the impact that the module has on a single design iteration. This represents an existing aircraft with a modified wing with an MLA system installed. Subsequently, the module is activated for the entire design process, to evaluate the effect that load alleviation has on cycled aircraft design. Both cases are evaluated twice, once featuring a stiff wing and once for a flexible wing, to assess the impact of aeroelasticity in wing design. The test case is represented by a single-aisle airplane, a design characterized by the ability to transport 150 to 200 passengers over a medium range, at a cruise Mach number of 0.78 .

\section{A. Effects of MLA in One-Cycle Design}

To investigate the effect of load alleviation on an existent design, first the baseline aircraft is designed. Subsequently, the new technology is imposed on the final wing design and the aircraft figures of merit, such as Maximum Take Off Mass (MTOM), Operating Empty Mass (OEM), fuel burn, and wing mass are evaluated and compared to the baseline. Both stiff and flexible wings are analyzed and the results are presented in the following paragraphs. Finally, a sensitivity study on the maximum allowed control surface deflection is realized. 


\section{MLA in One-Cycle Design for the Stiff Wing}

The wing is assumed to be completely rigid: all the three available control surfaces are allowed to deflect, to evaluate the impact of MLA on the wing structural design. The results are shown in Figure 7 As expected, the load alleviation optimization loop modified the lift distribution in order to increase the lift generated inboard, closer to the wing root, relieving the wing tip loading. The inboard flap would deflect downward, while the outboard flap and aileron would deflect upward. The result is a lower root bending moment, which leads to the desired reduction in wing mass of around of $10 \%$.

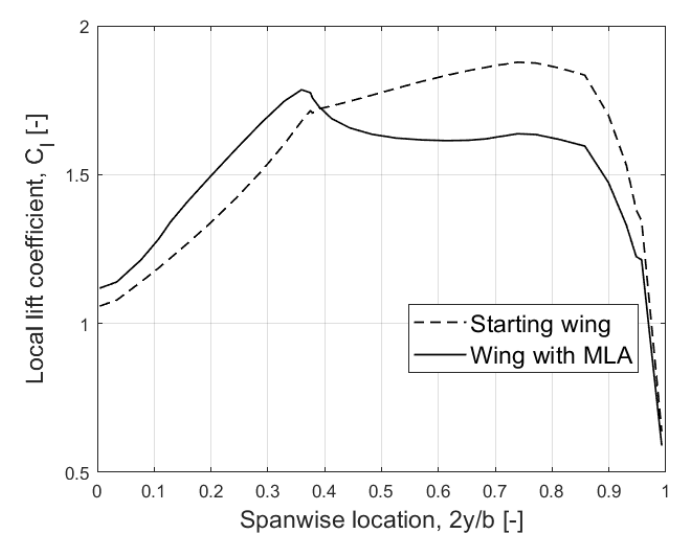

(a)

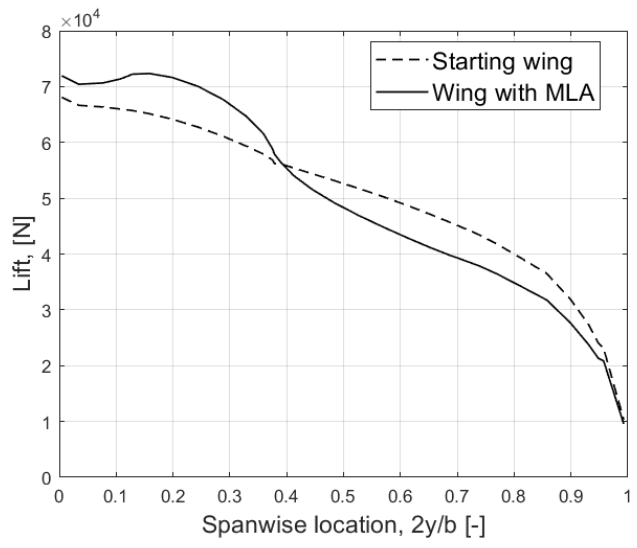

(b)

Fig. 7 Lift coefficient and lift distribution of 3 control surfaces MLA on the stiff wing

It is interesting to notice how the sizing maneuver with MLA active is at maneuver velocity $V_{A}$, while for the initial wing the sizing case was represented by $V_{D}$. This is due to the higher dynamic pressure in case of the dive speed maneuver: for a very similar lift coefficient distribution, the great difference in dynamic pressure for the two flight conditions leads to a substantial increase in inboard load achievable in the $V_{D}$ case and therefore to a more effective load alleviation capability at the dive speed. This means that the maneuver speed case $\left(V_{A}\right)$ is the sizing one when maneuver load allevaition is present. Also, the MLA module deflects the control surfaces to their limit deflections. This shows the high sensitivity of the load alleviation effect on this user specified boundary. It also exposes the limitation of the aerodynamic module, which is unable to assess flow separation, thus allowing for unlimited deflections.

Now, if the wing would hypothetically be substituted by the new, lighter version, the aircraft OEM would be reduced. The mission analysis module of the Initiator is then rerun, to estimate the impact of this mass reduction on the fuel needed to perform the harmonic mission, and therefore on the aircraft MTOM. The results of this analysis are presented in Table 3, which summarizes the effect of MLA technology on the one-Cycled aircraft design. As Table 3 states, a $10.3 \%$ wing mass reduction would lead to a $1.2 \%$ reduction in fuel burnt for the same harmonic mission.

Table 3 Effect of three control surfaces MLA on one-cycled design for the stiff wing

\begin{tabular}{ccccc}
\hline Stiff wing & Wing mass $[\mathrm{kg}]$ & OEM $[\mathrm{kg}]$ & Fuel mass $[\mathrm{kg}]$ & MTOM $[\mathrm{kg}]$ \\
\hline Baseline aircraft & 6695 & 39175 & 13660 & 73370 \\
3 control surfaces MLA & 6005 & 38490 & 13500 & 72525 \\
Difference \% & -10.3 & -1.7 & -1.2 & -1.2 \\
\hline
\end{tabular}

It is possible to use only one or a combination of the available control surfaces for load alleviation purposes. To investigate this opportunity, one control surface is activated at a time. The results in terms of mass percentage reductions are presented in Figure 8. As expected, when using all the three control surfaces, the benefits in mass reduction are higher. Both inboard flap and aileron show good results, while the outboard flap is the least effective. A combination of the inboard flap and the aileron also seems to be promising as the summation of their individual mass reductions are almost as much at the three control surfaces combined. 


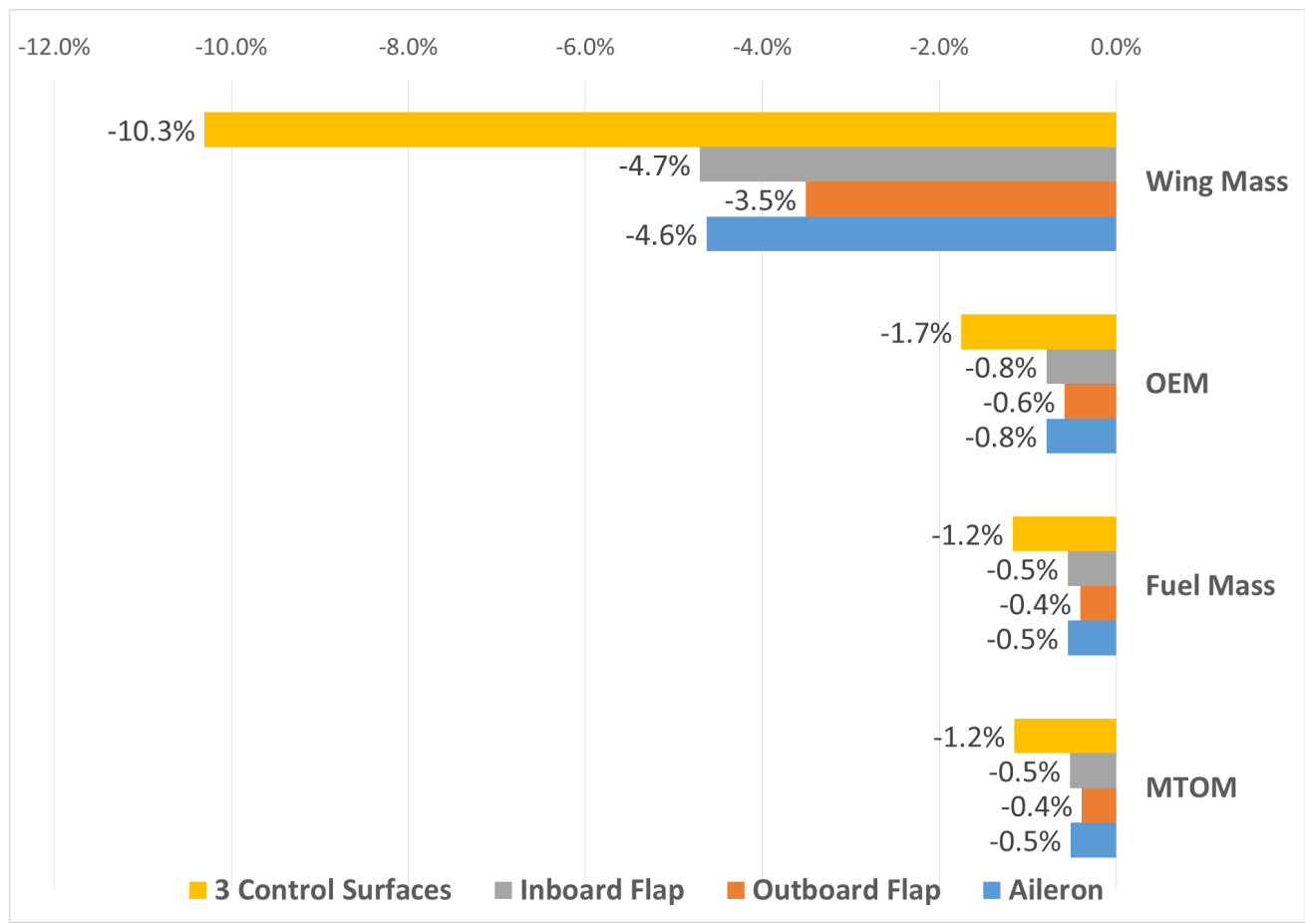

Fig. 8 Effect of MLA with different control surfaces for the stiff wing in 1-Cycle design

However, there are some drawbacks to this application which are not evaluated in this analysis. In fact, in order to utilize all three control surfaces for load alleviation, some extra actuators are needed: for instance, a typical flap is designed to deflect only downward, while for load alleviation the outboard flap is required to deflect upward. This requires a redesign of the control surface, which would lead to some unaccounted weight penalties. Furthermore, the deflection rate of the flaps may be not high enough for load alleviation purposes. Also in this case, the improvement of the existing actuators would lead to extra weight, which reduces the obtained benefits. A more detailed design is thus needed to precisely evaluate the final benefits of MLA technology. The aileron therefore represents the best choice, since it does not require any upgrade to be able to act as a load alleviation device, and it already shows good effectiveness, reducing both fuel burnt and MTOM by $0.5 \%$.

\section{MLA in Uncycled Design for the Flexible Wing}

As presented in Section [II.C] it is possible to correct the load generated by the wing by taking into account its flexibility. Figure 9 shows the alteration of the spanwise load of the starting wing due to structural flexibility, with no control surface deflected. As it is possible to notice from Figure 9, the wing flexibility acts like a load alleviation, increasing the load inboard and decreasing the load close to the wing tip. This is due to the tendency of the aft-swept wing to exhibit aerodynamic twist under the effect of vertical loads in such a way to reduce the local angle of attack at the tip. The maneuver load alleviation is again imposed to the flexible wing of the designed single-aisle aircraft, by using all three control surfaces. The result is presented in Figure 10

In Figure 10 the lift and lift coefficient distribution for the starting wing and the load alleviated wing, both stiff and flexible, are represented. It is possible to observe how the aeroelastic wing is able to reduce even more the outboard loads, increasing the effectiveness of the MLA. The final wing shows a $32 \%$ mass reduction with respect to the starting wing, which is more than double than the one in the stiff wing case. However, a more fair comparison is the difference in wing weight between the starting flexible wing and the flexible wing with MLA. Then the reduction is only $10.8 \%$, very close to the $10.3 \%$ that was found for the stiff wing.

Similarly as for the stiff wing, the wing is "substituted" and the mission is analyzed again, in order to assess the impact of the wing mass reduction on the aircraft design. The results are shown in Table 4 where the benefit comparison in terms of percentage reduction due to the use of the different control surfaces to achieve load alleviation is presented. As the wing weight reduction is greater than in the case of the stiff wing, also the overall benefits are increased. It is also 


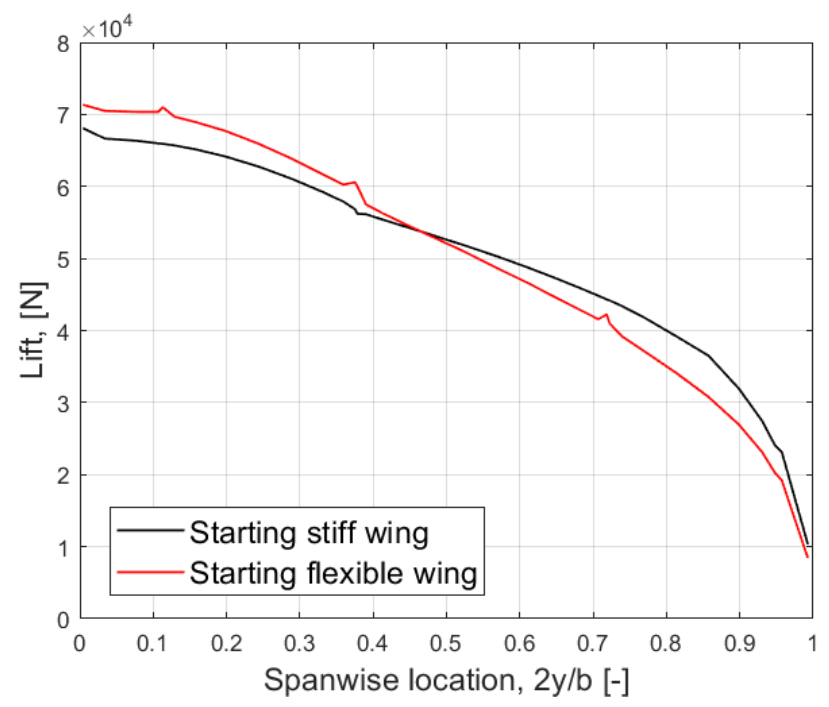

Fig. 9 Effect of wing flexibility on lift distribution

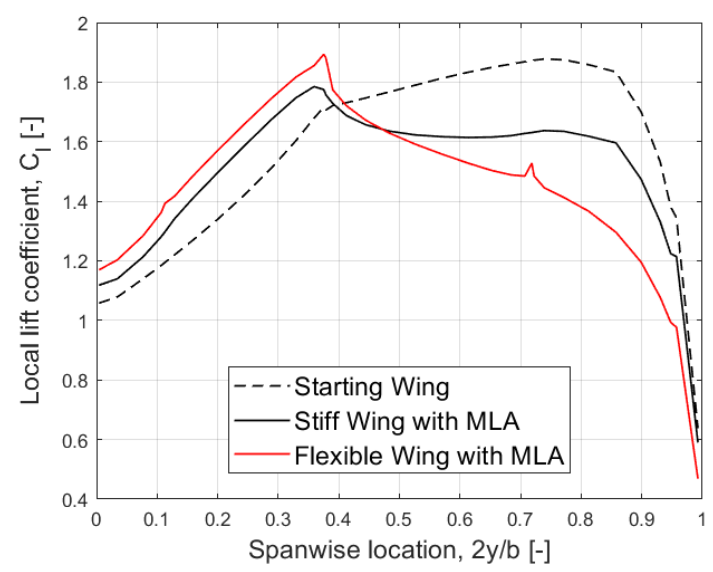

(a)

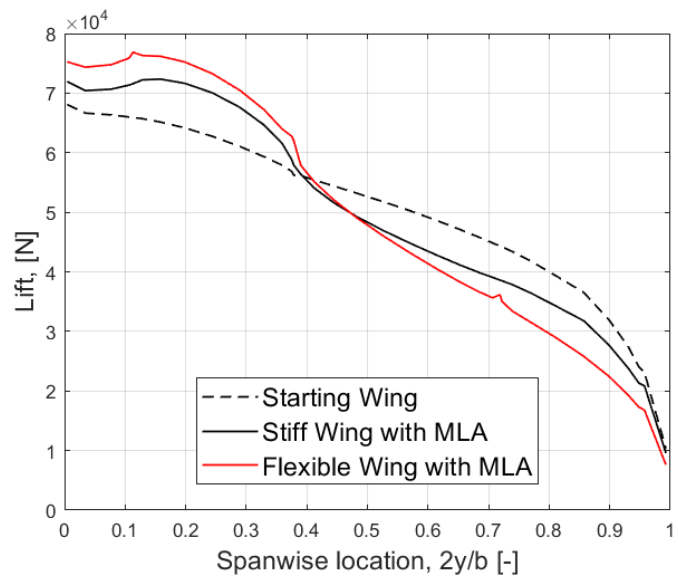

(b)

Fig. 10 Lift coefficient and lift distribution of 3 control surfaces MLA on the flexible wing

noted that the sizing condition for the flexible wing load alleviation is again $V_{A}$, even if the difference with the wing mass at the $V_{D}$ condition is small. Also for the flexible wing the most attractive configuration is to only use the aileron for load alleviation purposes. Together with the absence of drawbacks due to the actuators, this solution presents a $0.6 \%$ reduction in both burnt fuel and MTOM.

Table 4 Effect of MLA with different control surfaces on 1-Cycled design for the flexible wing

\begin{tabular}{ccccc}
\hline Flexible wing MLA & Wing mass [\%] & OEM [\%] & Fuel mass [\%] & MTOM [\%] \\
\hline 3 control surfaces & -10.8 & -1.8 & -1.2 & -1.2 \\
Inboard flap & -5.7 & -1.0 & -0.7 & -0.6 \\
Outboard flap surfaces & -4.6 & -0.8 & -0.5 & -0.5 \\
Aileron & -5.6 & -0.9 & -0.6 & -0.6 \\
\hline
\end{tabular}




\section{Sensitivity to maximum allowed deflection}

The maximum allowed deflection of the control surfaces is an important input parameter for the MLA module. It represents the upper and lower boundary of the optimizer, which is critical since the aerodynamic solver is not able to predict flow separation and thus to limit the control surface deflection. A sensitivity study is conducted, by varying this parameter from 0 to 13 degrees and allowing all three control surfaces to deflect. Figure11] shows the results of the sensitivity analysis. At zero deflection, the load alleviation is not active and the wing mass for the stiff wing is equal to the baseline aircraft. The weight reduction increases almost linearly when increasing the maximum allowed deflection.

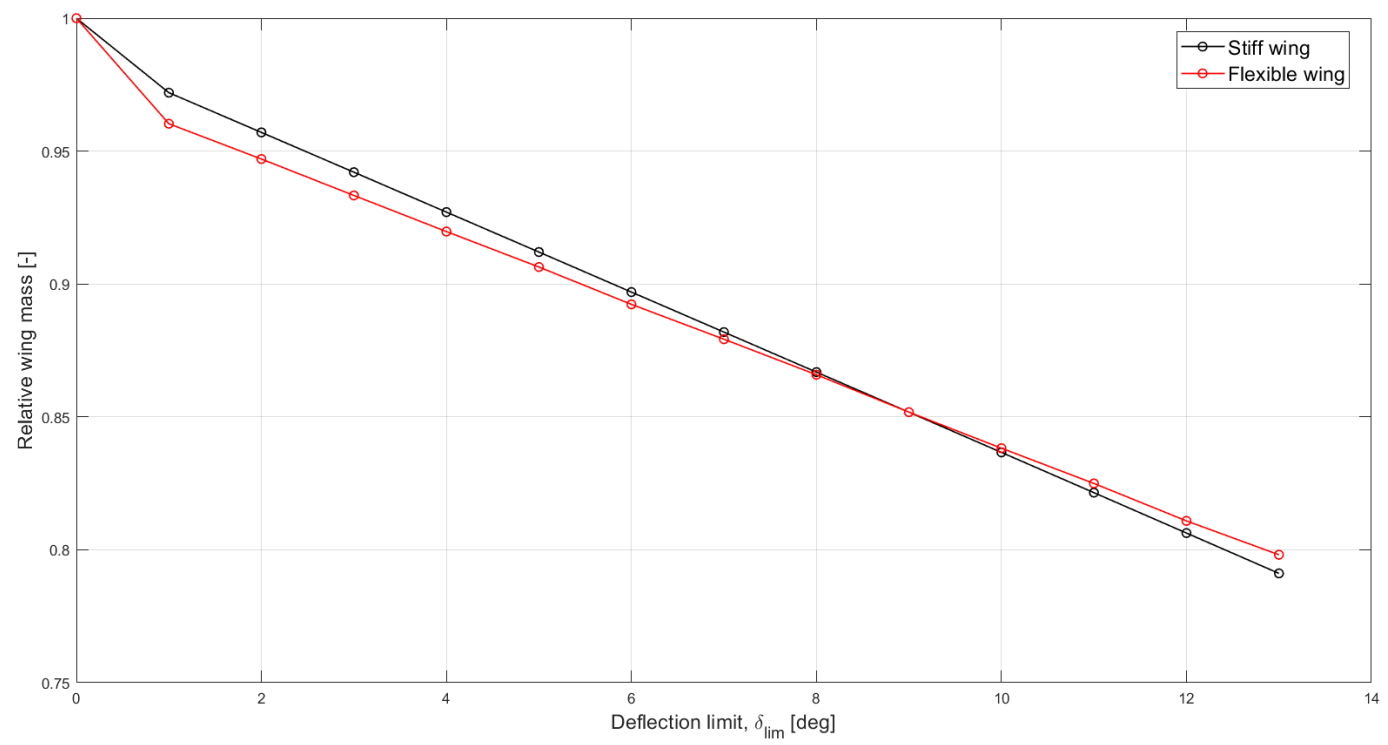

Fig. 11 Wing mass reduction sensitivity to control surface deflection limit

In case of the flexible wing, wing deflection acts as a load alleviation device, even when the control surfaces are not actuated, as previously discussed. The behaviour is similar to the one of the stiff wing, linearly decreasing the wing mass for greater deflection limits. It is possible to notice how for low deflection limits the flexible wing presents a slightly higher mass reduction, but it loses effectiveness for higher deflections. This is probably due to the deformed wing shape, which helps increase the load alleviation capabilities. However, since part of the load reduction is attained by wing deflection, the effectiveness of the control surfaces deflection is reduced.

\section{B. Effects of MLA in Cycled Design}

In this section, the load alleviation technology is active throughout the complete design process, to investigate the impact that such a technology can have on a clean-sheet design. Now, the updated operating emtpy mass and maximum take-off mass are used again in the Initiator loop to perform sizing of complete aircraft including the wing, the engines, the fuselage and the tail surfaces. Similar to the previous analysis, both stiff and flexible wings are evaluated. The configuration investigated are the ones involving all three control surfaces forload alleviation as well as the one using only the aileron. This is because the three control surfaces ensure the most benefits, while the aileron-only configuration presents the best benefits-over-complexity ratio, as previously discussed.

After the designs converge to a result, their parameters are compared to the baseline test case. In order to evaluate the effect of MLA in cycled aircraft design, the comparison is focused on specific performance areas: the wing mass, being the primary output of the MLA module, the aircraft MTOM, which is one of the main figures of merit in aircraft design, together with its components, the OEM and the fuel burn over the harmonic mission. The wing final geometry and the engine requirements are also analyzed. The results are collected and compared to the baseline design. Figure 12 shows the percentage difference between the designed aircraft equipped with MLA technology using all three control surfaces and the baseline design, for both stiff and flexible wing analyses.

As it is possible to notice in Figure 12, the final design confirms a reduction in wing mass due to the load alleviation technology, as expected, which directly leads to a reduction in operative empty weight and fuel burnt to complete the same mission. Therefore, also the maximum take-off mass is reduced. The flexible wing load alleviation appears to be 


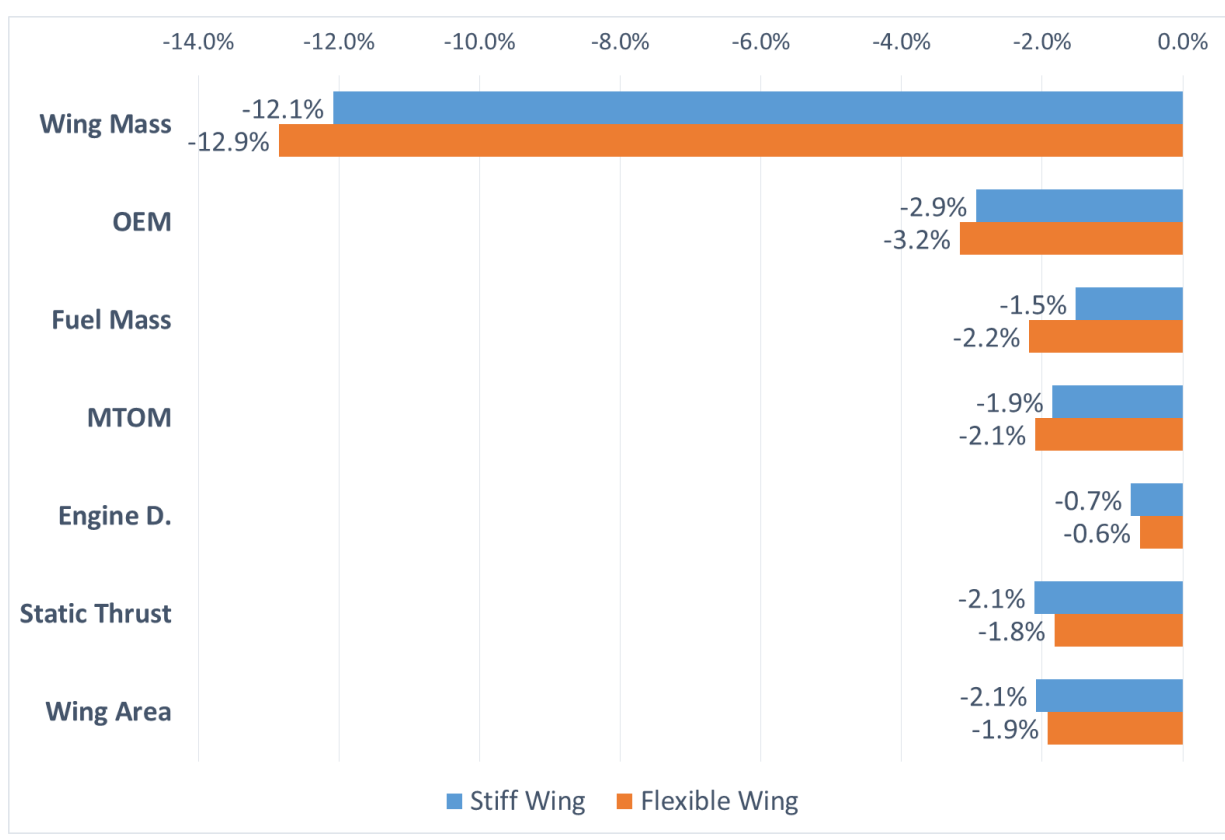

Fig. 12 Effects of three control surfaces MLA in cycled design

slightly more effective, since the fuel mass is $2.2 \%$ lower for the flexible wing, while $1.5 \%$ for the stiff assumption.

The reduction in overall aircraft weight affects also the engine requirements: in fact, the final engine diameter is reduced, as well as the required static thrust. This has benefits on the engine costs. The weight modifications have effects also on the wing geometry, which also shows a reduction of around $2 \%$. It is however interesting to notice that the flexible-wing case results in a slightly larger wing than the stiff-wing case.

It is interesting to notice how the final wing mass in the cycled design case is similar to the one-cycle case, while the benefits in terms of OEM and MTOM are at least 50\% higher in the cycled case. The overall reduction in MTOM and fuel burn are in fact greater for the clean sheet design. Therefore, the impact of a lower wing weight on important figures of merit such as the maximum take-off weight and the consumed fuel is more relevant if the load alleviation technology is considered since the start of the conceptual design. This conclusion is the same for the flexible-wing case. Similarly to the stiff case, the highest MTOM reduction is reached in the cycled design case, even if the wing mass is comparable.

\section{Conclusions}

A method to analyze the effect of load alleviation in conceptual aircraft design is presented. With this module, the effects of MLA technology on an existing and a clean-sheet design are evaluated and compared. At the same time, the impact of wing flexibility under maneuver load is assessed. The method is shown to correlate well to a higher-order method as well as to experimental results. Applying MLA to a redesign of only the wing can result in wing mass savings of up to $10 \%$ with a resulting reduction in maximum take-off mass and fuel burn of $1.2 \%$. Furthermore, it is shown that these results are sensitive to the predefined bounds on the control surface deflection and which of the wing movables are used to perform the load alleviation. By only applying symmetric aileron deflection can already result in a $0.5 \%$ reduction fuel burned over the harmonic mission. For the cycled design The results show a reduction in wing mass on the order of $12 \%$, which results in a maximum take-off mass reduction of up to $2 \%$ and a fuel burn reduction of $2.2 \%$. It is shown that the results of a rigid-wing assumption are very close to the results for the flexible wing in terms of wing mass and overall aircraft mass. It can therefore be concluded that a rigid-wing assumption is acceptable to be used during the conceptual design phase if the effect of maneuver-load alleviation technology is investigated.

\section{Acknowledgements}

This research is sponsored by the European Commission under the CleanSky II (Airframe) research program as part of project MANTA with grant agreement number 724558. 


\section{References}

[1] F. Rea, M. Arena, M. C. Noviello, R. Pecora and F. Amoroso, Preliminary failure analysis of an innovative morphing flap tailored for large civil aircraft applications, 2016 7th International Conference on Mechanical and Aerospace Engineering (ICMAE), London, 2016, pp. 534-542

[2] David A. Burdette, Gaetan K. Kenway, Zhoujie Lyu, and Joaquim Martins, Aerostructural Design Optimization of an Adaptive Morphing Trailing Edge Wing, 56th AIAA/ASCE/AHS/ASC Structures, Structural Dynamics, and Materials Conference, AIAA SciTech Forum, (AIAA 2015-1129)

[3] Rhea P. Liem, Gaetan K. W. Kenway, and Joaquim R. R. A. Martins, Multimission Aircraft Fuel-Burn Minimization via Multipoint Aerostructural Optimization, AIAA Journal, Vol. 53, No. 1 (2015), pp. 104-122

[4] Ed Obert, Aerodynamic Design of Transport Aircraft, IOS Press, 2009

[5] G. Molinari, M. Quack, V. Dmitriev, M. Morari, P. Jenny, P. Ermanni, Aero-Structural Optimization of Morphing Airfoils for Adaptive Wings, Journal of Intelligent Material Systems and Structures Vol 22, Issue 10, pp. 1075 - 1089, 2011

[6] Bret K. Stanford, Optimization of an Aeroservoelastic Wing with Distributed Multiple Control Surfaces, Journal of Aircraft, Vol. 53, No. 4 (2016), pp. 1131-1144.

[7] Masato Tamayama, Kanata Fujii, Tomohiro Yokozeki and Hitoshi Arizono, Study on Adaptive Wing Structure for Compromising Structural Strength and Aerodynamic Performance, International Forum on Aeroelasticity and Structural Dynamics, IFASD 2017, 25-28 June 2017, Como - Italy

[8] David A. Burdette, Gaetan K. Kenway, and Joaquim Martins, Performance Evaluation of a Morphing Trailing Edge Using Multipoint Aerostructural Design Optimization, 57th AIAA/ASCE/AHS/ASC Structures, Structural Dynamics, and Materials Conference, AIAA SciTech Forum, (AIAA 2016-0159)

[9] Silvestro Barbarino, Onur Bilgen, Rafic M. Ajaj, Michael I. Friswell, and Daniel J. Inman, A Review of Morphing Aircraft, Journal of Intelligent Material Systems and Structures Vol 22, Issue 9, pp. 823 - 877, 2011

[10] James Urnes and Nhan Nguyen, A Mission-Adaptive Variable Camber Flap Control System to Optimize High Lift and Cruise Lift-to-Drag Ratios of Future N+3 Transport Aircraft, 51st AIAA Aerospace Sciences Meeting including the New Horizons Forum and Aerospace Exposition Grapevine (Dallas/Ft. Worth Region), Texas

[11] Hans Peter Monner, Holger Hanselka, Elmar J. Breitbach, Development and design of flexible Fowler flaps for an adaptive wing, 5th Annual International Symposium on Smart Structures and Materials, 1998, San Diego, CA, United States

[12] Regan, Christopher D., Jutte, Christine V., Survey of Applications of Active Control Technology for Gust Alleviation and New Challenges for Lighter-weight Aircraft, Dryden Flight Research Center, Edwards, California, 2012

[13] Jia Xu and Ilan Kroo, Aircraft Design with Active Load Alleviation and Natural Laminar Flow, Journal of Aircraft, Vol. 51, No. 5 (2014), pp. 1532-1545

[14] David L. Rodriguez, Michael J. Aftosmis, Marian Nemec, and George R. Anderson, Optimization of Flexible Wings with Distributed Flaps at Off-Design Conditions, Journal of Aircraft, Vol. 53, No. 6 (2016), pp. 1731-1745

[15] JiGuan G. Lin, Reducing Induced Drag and Maneuver Loads by Active Aeroelastic Alteration, Journal of Aircraft, Vol. 53, No. 6 (2016), pp. 1787-1801.

[16] Andrew Ning and Ilan Kroo, Multidisciplinary Considerations in the Design of Wings and Wing Tip Devices, Journal of Aircraft, Vol. 47, No. 2 (2010), pp. 534-543

[17] Jia Xu and Ilan Kroo, Aircraft Design with Maneuver and Gust Load Alleviation, 29th AIAA Applied Aerodynamics Conference, Fluid Dynamics and Co-located Conferences

[18] Elmendorp, R.J.M., Synthesis of Novel Aircraft Concepts, Ph.D. thesis, TU Delft, 2014

[19] A.Elham, G.La Rocca, M.J.L.van Tooren, Development and implementation of an advanced, design-sensitive method for wing weight estimation, Aerospace Science and Technology, Volume 29, Issue 1, August 2013, Pages 100-113

[20] J.Szodruch, R.Hilbig, Variable wing camber for transport aircraft, Progress in Aerospace Sciences, Volume 25, Issue 3, 1988, Pages 297-328

[21] Ray Whitford, Design for air combat, Jane's, 1987 
[22] Mark Drela, Harold Youngren, (2017, February) AVL, Retrieved from AVL

[23] Joseph Katz, Allen Plotkin, Low-Speed Aerodynamics, Cambridge University Press, 2001

[24] Alan Williams, Structural Analysis: In Theory and Practice, Butterworth-Heinemann, 2008

[25] Federal Aviation Administration, FAA Regulations, Retrieved from FAA

[26] D. E.Raveh, Computational-fluid-dynamics-based aeroelastic analysis and structural design optimization - A researcher's perspective, Computer Methods in Applied Mechanics and Engineering, Volume 194, Issues 30-33, 12 August 2005, Pages 3453-3471

[27] D. E. Raveh, Maneuver Load Analysis of Overdetermined Trim Systems, Journal of Aircraft, Vol. 45, No. 1 (2008), pp. $119-129$.

[28] Robert D. Cook, David S. Malkus, Michael E. Plesha, Robert J. Witt, Concept and Application of Finite Element Analysis, 4th Edition, John Wiley \& Sons, 2001

[29] Leland M. Nicolai; Grant E. Carichner, Fundamentals of Aircraft and Airship Design, Volume 1 - Aircraft Design, AIAA Education Series, 2010

[30] Michael Chun-Yung Niu, Airframe Structural Design - Practical Design Information and Data on Aircraft Structures, Adaso/Adastra Engineering Center, 1975

[31] Werter, N.P.M., De Breuker, R., Aeroelastic Tailoring and Structural Optimisation using and Advanced Dynamic Aeroelastic Framework, IFASD 2015: 16th International Forum on Aeroelasticity and Structural Dynamics, Saint Petersburg, Russia, 28 June-2 July 2015

[32] Daniel Raymer, Aircraft Design: A Conceptual Approach, AIAA Education Series, 2012

[33] E. Torenbeek, Synthesis of subsonic airplane design, Delft University Press, 1982 